\title{
Agriculture history and policy
}

\author{
Abdulgani Devlet ${ }^{1}$ \\ ${ }^{1}$ Faculty of Agiruculture and Natural Science, Bilecik Şeyh Edebali University \\ Bilecik, Turkey
}

\begin{abstract}
The ancient Fertile Crescent in particular, is commonly comprehended as the origin of agriculture. The location of Western Asia covers the area of Mesopotamia and the Levant, and is limited by Syrian Desert to the south and the Anatolian Plateau to the north. First of all, a good diagnosis is needed to treat the disease, it is necessary to make a good diagnosis and definition for our sectors such as agriculture which connects our past, current and future life. In the agricultural sector, like other sectors, if we ask for a timely diagnosis and treatment of issues; certainly, we don't have to demand more because of neglect. The basis of the agricultural sector also is a science. World population has been growing and natural resources such as land and water is already under stress. To make a nation healthy and to meet food demand along with nutrition security, agriculture would continue remain as the top most priority sector for any country. Agriculture provides food, fibre and raw materials to industry. It contributes significantly to Gross Domestic Product (GDP). Agriculture provides cleaner, better environment for people to lead healthy life on earth. Moreover, it provides employment to large section of the people. If a nation has to be strong, then it has to be self-reliant coupled with strong agricultural economy that supports ecological and nutritional security. The history of agriculture has showed an important value in human development. More than half of all human around the World once efforted in farming, and even today, few-if any-humans could survive without it.This paper depicts the agricultural history and policy reforms and structural changes in World from past to the current times.
\end{abstract}

Article History

Received 31.12.2019

Accepted 15.02.2020

\section{Introduction}

The most important change in human history begins with the development of agriculture. Scholars from many disciplines, such as religiology, archaeology, historical linguistics, biology, anthropology and history, have investigated southwest Asia, South Asia, China, Japan, Southeast, Middle East, Asia and Pacific, sub Saharan Africa, America and Europe,

${ }^{1}$ Correspondence: abdulgani.devlet@bilecik.edu.tr 
and studied the common development of agriculture with social structure and cultural forms (Barker and Goucher, 2015).

The Food and Agriculture Organization of the United Nations estimates that by 2050, we will need $60 \%$ more food. Agriculture must provide more and more high-quality food, fiber, feed and fuel for human beings in an environmentally, economically and politically sustainable way. And agriculture will become more challenging in the future, and the development and correct implementation of precision agriculture will help to achieve this very important task (Zhang, 2016). The link between agriculture and human needs requires reducing pollution in the areas of air, soil and water, improving food production and related socio-economic issues, with a focus on human health and livelihoods. For sustainalable agriculture, four pillars are land management, resource management, human interface and ecosystem interface. Because of the strong influence of personal values, culture, norms and habits, the human interface may be the most unpredictable and complex (Peattie, 2010). Domestication of plants for thousands of years has led to extreme changes in human diet and social development, prompting people to eat more grains. At present, carbohydrates still account for $60 \%$ of human calories (Foster et al., 2003), most of which are consumed by grains such as rice, wheat and corn. Both animals and plants in the area have experienced extensive expansion. Once domestication is successful, it will be scattered from the origin area to another part of World. Domestication began with wheat cultivation in Fertile Crescent areas such as Turkey and spread rapidly throughout Europe (Zohary et al., 2012). With the improvement of domestication, the human diet structure has been accelerated, but it is still changing. Urbanization involves more consumption of polished grain (bran removal). Rice and wheat have been treating for more sugar, more animal products and, more food (Drewnowski and Popkin, 1997). Grain production accounts for a large part of the world's agricultural production. According to FAO, world grain production is expected to reach the target of 3 billion tons by 2050 (Alexandratos and Bruinsma, 2012).

The first challenge facing World Agriculture is to produce enough food to meet the growing world population. It is predicted that the world population will reach 8 billion by 2025. It is expected that in the coming decades, the population in rural areas will decrease, and rapid urbanization will lead to the continued growth of urban population. So far, the income of agricultural activities is low and about $70 \%$ of the poor are still rural residents. The second challenge for World Agriculture, therefore, is technical, policy and institutional. 
Meeting this challenge will require farmers to have access to domestic and international markets. The third challenge facing World Agriculture is that small-scale farmers pay attention to the long-term management of the natural resources they manage. In the new century, we will create a set of technologies, incentives and policies to encourage development. Around the world, it is vital that most of the fields, Forests and pastures are used by farmers. Agricultural water consumption accounts for more than $70 \%$ of the world's fresh water, and there are a lot of biodiversity in the agricultural system. It is estimated that agricultural production can cause $70 \%$ of the water area, deforestation of most forests and loss of biodiversity (Zocca et al., 2018). The border between the forest and the desert is affected by agricultural activities. Therefore, the issue of improving our natural resource management is closely related to improving the productivity and profitability of small-holder farmers in developing countries. However, there is a huge pressure on agricultural production systems to cope with increasing demand, climate and soil change. This is mainly due to human interference. The increasing of food production in the case of reduced land per capita and water shortage must be described for humankind (Postel, 1996). With the increase of food production, especially the source of high protein food, how to meet the future needs of the population is facing some challenges (Singh-Ackbarali and Maharaj, 2017); currently entering a new era of agriculture, scientists are developing "intelligent" plants to achieve healthy life to save the future. Human beings always equate their happiness with consumption. Therefore, increasing production has become the competition problem of every country. This, in turn, brings a burden to the environment due to the abuse or overuse of natural resources (Singh, 2018).

Thousands of years of plant domestication have led to extreme changes in the human diet, as well as social development, driving to a greater consumption of grains. Carbohydrates are still serving about $60 \%$ of our calories today (Foster et al., 2003). Most of these carbohydrates are consumed as grains (mainly rice, wheat, and maize). Most domesticated plants and animals experience widespread expansion. Once domesticated successfully, these crops and animals expand rapidly and are used in areas where they did not originate. Clearly, the human diet has dramatically altered with increased domestication and is still changing today. Urbanization is involved with greater consumption of polished grains (bran layer removed), where rice and wheat are preferred over grains such as millet, more sugar, more animal products, and most importantly more food is consumed away from home (Drewnowski and Popkin, 1997). 
Domestication began with the cultivation of wheat in the Fertile Crescent and rapidly spread all over Europe (Zohary et al., 2012). In contrast, recent analyses suggests that new technology, economic, and environmental factors are the driving trends of increase in local production, manufacturing, and services, a process named "deglobalization" (Hammes, 2016).

Human beings always equate their well-being with consumption. Therefore, every nation rich or poor is in a race to increase production. This in turn is putting a burden on the environment due to misuse or overuse of natural resources. Actually around $60 \%$ of the total waste generated from industrial, agricultural, or domestic sectors is biodegradable and can be used for production of economically important plants and nutritionally balanced animal proteins. Vermicomposting is one such technology that synergizes microbial degradation with earthworm's activity for reducing, reusing, and recycling waste materials in a shorter span of time. Mutual action of earthworms and microbes brings faster decomposition as earthworms aerate, condition, fragment, and enhance surface area of the organic matter for microbial action (Singh, 2018).

The interface between human demand and agriculture requires efforts to reduce pollution in the air, soil, and water spheres and improve socioeconomic-related issues in food production with an emphasis on human health and livelihood. The human interface may be the most unpredictable and complex of the four pillars (land management, resource management, human interface, and ecosystem interface) as it is influenced strongly by personal values, culture, norms and habits (Peattie, 2010).

Processing of foods is an important topic since $30 \%$ of the overall production of food is lost postharvest (FAO, 2013) because of lack of appropriate technologies and techniques for preservation. In the food industry, the control of unwanted microorganisms is essential and decisive (Stoica et al., 2011). The soil is deposited on food processing equipment and forms films that negatively interact with the processing integrity lines, for example, on the walls of an empty tank and on the internal surface of a heat exchanger (Norton and Tiwari, 2014).

In the food systems, the way of production and distribution, as well as the kind of foods we consume can have a certain effect on the planet where we are living on and the society which we are living in. Air, water, land, climate conditions, and biodiversity are the major driving forces for human well-being and, at the same time, major parts of our lives are exposed to 
human activities intentionally. Sustainability of these natural sources plays a primary role in the food systems. However, food system itself also has a primary role for protecting natural sources because of its certain consequences such as greenhouse gas (GHG) emissions, water and soil pollution, and deforestation (Garnett, 2013).

Nowadays, the definition of food security focuses on the access to food rather than food production. In November 1999, The World Food Summit took place with a participation of 185 countries and the European Community for the eradication of hunger. According to definition of World Food Summit (FAO, 1996), food security is met when "all people, at all times, have physical and economic access to sufficient, safe, and nutritious food to meet their dietary needs and food preferences for an active and healthy life." Food and nutrition security are considered as the priorities of food system outcomes and strongly emphasized in the definitions of "sustainable diet" that is comprised of a healthy diet and a healthy environment (Allen and Prosperi, 2016).

Earlier, in 2011, Food and Agricultural Organization (FAO) published a report considering global food losses and food wastes noting that nearly one-third of worldwide food production (1.3 billion ton/year) for human consumption is lost or wasted. The amounts of food loss and waste along the food supply chains, respectively, are 54\% of total loss and waste as upstream processes (including production and postharvest) and $46 \%$ of total loss and waste as downstream processes (including processing, distribution, and consumption) (FAO, 2011). The European Commission technical report (published in 2010) indicated that around 90 million tonnes of food wastes are generated within European Union (EU) each year.

The percentage breakdown of food wastes according to this report is $39 \%$ manufacturing, $42 \%$ households, $14 \%$ food service/catering, and 5\% retail/wholesale (2006 EUROSTAT data and various national sources provided by EU Member States). Based on this study, it is expected that food wastes would reach 126 million ton in 2020 (from about 89 million ton in 2006), without additional prevention policies or activities. From 2006 up to 2020, food waste tonnages are expected to be 3.7 million in EU27 when population increases by nearly 21 million (Otles et al., 2015).

Food supply chains begin from the primary agricultural phase, proceed with manufacturing and retail, and end with household consumption. During this life cycle, food is lost or wasted because of technological, economic, and/or societal reasons. The definitions of "food waste" 
and "food loss" within the supply chain have been a subject of disagreement among the related scientists. According to the EU Commission Council Directive, 2008/98/ EC, "waste" is defined as "any substance or object, which the holder discards or intends or is required to discard." "Food loss" refers to quantitative and qualitative reductions in the amount and value of food. The qualitative loss corresponds to the loss of caloric and nutritive value, loss of quality, and loss of edibility. Quantitative loss refers to the decrease in edible food mass throughout the part of the supply chain that specifically leads to edible food for human consumption. FAO (2015) global voluntary definitional framework defined food loss as the decrease in quantity or quality of food, caused mainly by food production and supply system functioning or its institutional and legal framework. Thereby, "food loss" occurs throughout the food supply chain. Moreover, FAO distinguishes "food waste" as an important part of "food loss," which refers to the removal of food from the supply chain, which fits for consumption by choice or has been left to spoil or expire as a result of negligence (predominantly but not exclusively) by the final consumer at household level.

Food supply carries a vital importance for human survival. Nevertheless, the protection of natural resources which is tightly coupled with food supply is an inevitable priority in today's world. The fact of increasing soil, water and air pollution, deforestation, the decline in biodiversity and effects of climate change and in response to all these events, ever-growing human population and the needs for food and energy create a very serious problem to provide continuance of human survive. All these factors constitute certain unsustainability in the global agriculture and food systems, and the generation of huge amount of food waste became a major indicator of this instability.

Food industry has to produce enough food and ensure the food safety while giving rise to a less environmental impact. The improvement of food production efficiency, the prevention of food waste generation, and waste valorization for meeting the increasing demand for chemicals, materials, and fuel are the only solutions to restore this unsustainability. Appropriate waste management strategies including the prevention of unsustainable use of natural sources, huge amount of waste generation, and the recommendation of a more costeffective and environment friendly disposal system should be a global focus point which is shared by farmers, industrial producers, consumers, and policy makers (Otles and Karta, 2018). 


\section{Definition of Agriculture}

Agriculture is a science, art or practice of growing soil, producing crops and raising animals for marketing. Agriculture is the most basic instinct of human beings, which has a broad definition such as the ability to produce food to meet hunger and the survival of species. The word 'Agriculture' is originated from the Latin word 'Ager' means field and 'Culture' means cultivation. So agriculture is an art of raising living organism from the earth for the use of human being (Alexandratos et al., 2006) We shall understand agriculture as consisting of activities which foster biological processes involving growth and reproduction to provide resources of value. Typically, the resources provided are plants and animals to be used for food and fiber, although agricultural products are also used for many other purposes (Lehmen et al., 1993).

Sustainable agriculture is one of the best practices for environmental sustainability. It maintains the fertility of soil and ecosystem and human's health. It relies on improved ecological processes and cycles of local adaptation, as well as natural biodiversity, rather than the use of synthetic inputs and genetically modified materials. Therefore, farmers must be encourage to engage advance agriculture for future. It has the great potential to contribute to food security and economy (FAO, 2013).

\subsection{Agricultural History}

World agricultural land is very rich. Some local elders and historians believe that their origin story proves that they have always had agriculture. From past to now agriculture is not yet a major economic activity. Farmers has been doing agriculture activities for survive and support their families. It is very clear that if many of the sub themes that others will emphasize when writing similar works are strictly excluded, and if the book's claims are not so moderate, it will be criticized. Understanding our history also helps us to meet today's local, national and global challenges. Hot issues such as environmental protection, land-use policies and ensuring adequate food supply are not new debates. They come in other times and forms. A deep understanding of the history of agriculture provides the basis for today's agricultural policy (Apple et al., 2015). No matter what the motives of Americans and Europeans are, they are most concerned about making a living. Most newcomers immediately 
began to produce their basic products with the initial goal of making a living, but it is expected that surplus products will soon be sold in local or national markets.

\subsection{Agricultural Policy}

In the past 20 years, the traditional agricultural policy agenda and new policies have been challenged. "Agricultural income" is no longer the main concern although food security is a policy concern after the food price panic at the end of this century, adopting a more westernized diet may lead to a 50\% increase in food demand (Huang et al., 2010). The new emergence includes food safety, the provision of environmental and ecosystem services, the role of biotechnology in agricultural production (especially genetically modified organisms, genetically modified organisms), intellectual property rights and biological patents, the use of farmland to produce bioenergy, and the role of the agricultural sector in reducing climate change.

In developing countries, the policy and practice of developing industry at the expense of agriculture has been abandoned, with "development" and "agriculture" as the central policy instead. New policy issues are being addressed in a more flexible institutional environment. In such an environment, there are often conflicts and interactions among regions and institutions based on different values, so policy coordination is needed. This coordination process is called inter agency decision-making. We should encourage participation in the formulation of new agricultural policies. Design and implement policies more effectively. Value balance has become a key feature of the new politics of agriculture and food (World Bank, 2008).

In the past, the research on agricultural decision-making has promoted the development in many political theoretical fields, such as interest groups, policy networks and public policy ideas. The study of these concepts is based on agricultural policy, and often from the agricultural sector to illustrate the theoretical point of view. It makes the agricultural policy department benefit to divide the policy-making process, well-organized policy-making process and agricultural groups with sufficient resources, the government's massive intervention in the market, and the possibility of significant redistribution of income and wealth among economic actors (Daugbjerg and Botterill, 2012). 
In order to promote greater agricultural production and linkages with other sectors, more targeted agricultural measures are needed. This may include further integration of food production to provide value-added and market access for food producers in the domestic tourism sector. It is more necessary to provide targeted agricultural funds in order to create more value-added agricultural industries and establish links with services and manufacturing industries. In order to create opportunities that directly benefit the rural population, partnerships among rural agricultural producers, governments and industry must be strengthened. We will provide more targeted agricultural financing, and set up the agricultural and food production insurance market for domestic producers. Invest in agricultural and food infrastructure, such as training and skills development, to improve roads and logistics capabilities, refrigeration facilities, food processing and value-added (Gani and Scrimgeour, 2019).

Agricultural policies that encourage mass production lead to highly concentrated agricultural practices that are likely to lead to environmental degradation. For example, fossil fuels are used to produce and transport chemical fertilizers and pesticides over long distances; then, raw products and finished products are further transported; water sources are also transported to agriculture; used water is often polluted by chemical fertilizers and pesticides, resulting in "dead zones" in the downstream. Consumers' food prices do not include the actual cost of their production. The actual costs include the cost of environmental clean-up, the cost of toxic exposure to human health and the lack of clean water, the cost of fossil fuel overuse, and the cost of food growth for future generations, while agricultural losses will be significantly reduced. Our current agricultural policies run counter to our nutritional, environmental and economic needs. Agricultural policies should not harm the health of the public, especially our children. Nor should it promote or allow our natural environment to continue to deteriorate. A healthy food system should ensure the well-being of consumers and farmers, as well as the producers, processors and distributors on which they depend. Organic and regional food production are promising examples of change. Unhealthy people in unhealthy places cannot produce healthy food. It is the responsibility of the health community to ensure the conditions for people's health. This means participating in agricultural policies to influence better food supply (Jackson et al., 2009). Someone may be a good manager, but being a good politician is another matter. Be able to accept the experience of the past society to guide the future. Agricultural policies are very important for human and environmental health. It is always useful to fully grasp the agricultural and sideline industries and eliminate 
the harm. Access to and maintenance of a healthy life should be the goal of agricultural policy. As a person, a society, a country, this is unchangeable. This policy is crucial to the economy, business and industry. People can't understand the value of two things at any time: time and health. It should be such a state that the management of a family in a society is basically similar to that of a country.

\section{Conclusion}

Although the agricultural structure has changed significantly and dramatically beyond some elements, the agricultural production sector is still composed of agricultural units owned and operated by families. Still most important are inputs such as rainfall, sunlight and temperature. As a result, changes in climate, topography, soil and other agro ecosystems continue to affect production options for crops and livestock. In turn, the changes of these natural factors affect the implementation of management and technology selection. It can be seen that family decentralized farm management has advantage. Capital and other technologies have replaced or improved the impact of these natural changes. The nature and speed of technological changes aimed at influencing agricultural production, as well as more general production options. The change of agricultural structure coincides with the increase of animal raising efficiency and the decrease of production cost. The increase of productivity is mostly due to the increase of production scale and technological innovation (Key et al., 2007).

In the toolbox of public policy analysis, the theory of policy stability is explained through new corporatism, policy network analysis and new system focusing on path dependence. It is proved that it is effective to determine the mechanism of returning stable agricultural policy path over time. It also emphasizes the importance of compartmentalizing policy-making and involves only a limited number of shared ideas and values of interest. The previous wave of policy reform has drawn the attention of policy analysts to the development theory and analysis framework, which can be used to explain these change multi flow models, punctuation equilibrium model, advocacy alliance framework and concept theory. These theories are the same as "stability theory", that is, the concept of conventional decisionmaking in relatively closed and exclusive subsystems, or networks (Daugbjerg and Botterill, 2012). 
Grant (2012) said that by using new modes of action (such as social media), new participants may be able to "debate. As a result, these new actors may successfully launch and promote through policy and institutional reforms. Inter agency coordination links core policy sectors to new policy areas that have not previously been approached by core policy sectors. The lower political cost strategy proposed by such new actors may be to initiate a policy level process in which new policy concerns are addressed by adding new measures to existing core policies. The concept of policy stratification has not been clearly defined, but the definition of institutional stratification by Thelen (2003) may also cover policy stratification. Stratification refers to a "retention of the core (of an institution) while adding amendments through which rules and structures inherited from the past can be synchronized with changes in the normative, social and political environment".

The case study also shows that this is not an easy process, which may lead to the ecological corporatization of policy stratification and the value balance involved in inter agency policymaking. Kay and Ackrill (2012) and Daugbjerg and Botterill (2012) have shown that although this may only have the potential to internalize value conflicts in the short and medium term, value can be balanced through policy stratification. Due to the change of political or economic relations, the value balance has changed. The most stable solution for inter agency policy. Just as Cockfield and Botterill (2012) made decisions when an overall value dominates the policy complex. In the agricultural policy sector, decentralization and inter agency decision-making are becoming increasingly important. It is possible to provide the same theoretical insights as the traditional agricultural policy research in the past. As in the past, contributors to this topic have been firmly involved in the broader theoretical development of political science, enabling them to draw more general lessons from case studies (Daugbjerg and Swinbank, 2012).

\section{References}

Alexandratos, N., Bruinsma, J. 2012. World agriculture towards 2030/2050: the 2012 revision. ESA Working paper No. 12-03. FAO, Rome.

Alexandratos, N., Bruinsma, J., Bodeker, G., Schmidhuber, J., Broca, S., Shetty, P., Ottaviani, M.G. 2006. World Agriculture: Towards 2030/2050. Interim Report. Prospects for Food, Nutrition, Agriculture and Major Commodity Groups.

Allen, T., Prosperi, P. 2016. Modeling sustainable food systems, Environmental Management, 57: 956-975. 
Apple, F.S., Jaffe, A.S., Collinson, P., Mockel, M., Ordonez-Llanos, J., Lindahl, B., Hollander, J., Plebani, M., Than, M., Chan, M.H. 2015. IFCC educational materials on selected analytical and clinical applications of high-sensitivity cardiac troponin assays, Clinical Biochemistry, 48: 201-203.

Barker, G., Goucher, C. 2015. The Cambridge world history, a world with agriculture, Volume II. Cambridge University Press, England.

Cockfield, G., Botterill, L.C. 2012. The evolution of rural policy: The antipodean experience, Policy and Society, 31: 343-353.

Daugbjerg, C., Botterill, L.C. 2012. Ethical food standard schemes and global trade: paralleling the WTO?, Policy and Society, 31: 307-317.

Daugbjerg, C., Swinbank, A. 2012. An introduction to the 'new' politics of agriculture and food, Policy and Society, 31: 259-270.

Drewnowski, A., Popkin, B.M. 1997. The nutrition transition: new trends in the global diet, Nutrition Reviews, 55: 31-43.

FAO. 1996. Rome declaration on world food security and world food summit plan of action, http://www.fao.org/docrep/003/w3613e/w3613e00, (December, 2019).

FAO. 2011. Global food losses and food waste: extent, causes and prevention. Food and Agriculture Organization of the United Nations, Rome.

FAO. 2015. Definitional framework of food loss, http://www.fao.org/3/a-i4068e.pdf, (December, 2019).

FAO. 2013. Food wastage footprint summary report, http://www. fao.org/docrep/018/i3347e/i3347e.pdf, (December 2019).

Foster, G.D., Wyatt, H.R., Hill, J.O., McGuckin, B.G., Brill, C., Mohammed, B.S., Szapary, P.O., Rader, D.J., Edman, J.S., Klein, S. 2003. A randomized trial of a low-carbohydrate diet for obesity, New England Journal of Medicine, 348: 2082-2090.

Gani, A., Scrimgeour, F. 2018. Trade, agriculture and inter-industry spillover effects in Fiji, Journal of Developing Regions, 53: 193-206.

Garnett, T. 2013. Conference on 'Future food and health'symposium I: sustainability and food security food sustainability: problems, perspectives and solutions, Proceedings of the Nutrition Society, 72: 29-39.

Grant, W.P. 2012. Can political science contribute to agricultural policy?, Policy and Society 31: 271-279.

Hammes, T. 2016. Will technological convergence reverse globalization? Strategic forum. National Defense University Press. Washington, DC, USA.

Huang, H., Legg, W., Cattaneo, A. 2010. Climate change and agriculture: The policy challenge for the 21st century?, EuroChoices, 9(3): 9-14.

Jackson, J.J., Minjares, R., Naumoff, K.S., Shrimali, B.P., Martin, L.K. 2009. Agriculture policy is health policy, Journal of Hunger \& Environmental Nutrition, 4: 393-408.

Kay, A., Ackrill, R. 2012. Governing the transition to a biofuels economy in the US and EU: Accommodating value conflicts, implementing uncertainty. Policy and Society, 31: 295306.

Key, Nigel D., McBride, William D. Production contracts and farm productivity: Examing the link using instrumental variables. American Agricultural Economics Association (AAEA), Annual Meeting, 29 July - 1 August 2007, Portland, Oregon.

Lehmen, H., Ann Clark, E., Weise, S.F. 1993. Clarifying the definition of sustainable agriculture, Journal of Agricultural and Environmental Ethics, 6(2): 127-143.

Norton, T., Tiwari, B.K. 2014. Sustainable cleaning and sanitation in the food industry. In: Tiwari, B.K., Norton, T., Holden, N.M. (Eds). Sustainable Food Processing. John Wiley \& Sons. Oxford. pp. 363-375. 
Otles, S., Despoudi, S., Bucatariu, C., Kartal, C. 2015. Food waste management, valorization, and sustainability in the food industry. In: Galanakis, C.M. (Ed). Food Waste Recovery: Processing Technologies and Industrial Techniques. Elsevier Inc., Waltham. pp: 3-23.

Otles, S., Karta, C. 2018. Food waste management. In: Galanakis, C.M. (Ed). Sustainable Food Systems from Agriculture to Industry, Improving Production and Processing. Academic Press, Elsevier. pp. 371-399.

Peattie, K., 2010. Green consumption: behavior and norms, Annual Review of Environment and Resources, 35: 195.

Postel, S. 1996. Dividing the water: food security, ecosystem health, and the new politics of scarcity. Worldwatch Paper no: 132. Worldwatch Institute, Washington DC.

Singh-Ackbarali, D., Maharaj, R. 2017. Mini livestock ranching: solution to reducing the carbon footprint and negative environmental impacts of agriculture. In: Ganpat, W., Isaac, W. (Eds). Environmental Sustainability and Climate Change Adaptation Strategies. IGI Global, The United States of America. pp. 188-212.

Singh, J., 2018. Role of earthworm in sustainable agriculture. In: Galanakis, C.M. (Ed). Sustainable Food Systems from Agriculture to Industry, Improving Production and Processing. Academic Press, Elsevier. pp. 83-122.

Stoica, M., Bahrim, G., Cârâc, G. 2011. Factors that influence the electric field effects on fungal cells. In: Méndez-Vilas, A. (Ed). Science Against Microbial Pathogens: Communicating Current Research and Technological Advances. Formatex Research Center. Badajoz. pp. 291-302.

Thelen, K. 2003. How institutionalism evolve: Insights from comparative historical analysis. In: Mahoney, J., Rueschemeyer, D. (Eds). Comparative historical analysis in the social sciences. Cambridge: Cambridge University Press. pp. 208-240.

World Bank. 2008. World development report: Agriculture for development. Washington, DC: World Bank.

Zhang, Q. 2016. Precision agriculture technology for crop farming. CRC Press. Taylor \& Francis Group. London. New York.

Zocca, R.O., Gaspar, P.D., da Silva, P.D., Nunes, J., de Andrade, L.P. 2018. Introduction to sustainable food production. In: Galanakis, C.M. (Ed). Sustainable Food Systems from Agriculture to Industry, Improving Production and Processing. Academic Press, Elsevier, pp. 3-46.

Zohary, D., Hopf, M.,Weiss, E. 2012. Domestication of plants in the old world: the origin and spread of domesticated plants in Southwest Asia, Europe, and the Mediterranean Basin. Oxford University Press, Oxford. 